\title{
Peertechz
}

\section{Clinico-Biochemical findings associated with stage III and stage IV of Chronic Kidney Disease in dogs}

\section{Vinodhini Jayananthan ${ }^{1 *}$, Abiramy Prabavathy $A^{2}$, Uma $\mathrm{S}^{3}$, Barathiraja $\mathrm{S}^{4}$, Rajkumar $\mathrm{K}^{2}$, Thanislass $\mathrm{J}^{5}$ and Vijayalakshmi $\mathbf{P}^{6}$}

'UG student (B.V.Sc\&A.H.) Rajiv Gandhi Institute of Veterinary Education and Research, Pondicherry, 605009 , India

${ }^{2}$ Professor and Head, Department of Veterinary Medicine, Rajiv Gandhi Institute of Veterinary Education and Research, Pondicherry, 605009, India

${ }^{3}$ Assistant Professor, Department of Veterinary Pathology, Rajiv Gandhi Institute of Veterinary Education and Research, Pondicherry, 605009, India

${ }^{4}$ Professor and Head, Department of Veterinary Biochemistry, Rajiv Gandhi Institute of Veterinary Education and Research, Pondicherry, 605009, India

${ }^{5}$ Professor and Head, Department of Veterinary Biochemistry, Rajiv Gandhi Institute of Veterinary and Education, Pondicherry, 605009, India

${ }^{6}$ Professor, Department of Veterinary Medicine, Rajiv Gandhi Institute of Veterinary Education,

Pondicherry, 605009, India
Received: 30 October, 2021

Accepted: 24 November, 2021

Published: 25 November, 2021

*Corresponding author: Vinodhini Jayananthan, Department of Veterinary Medicine, Veterinary Clinical Campus (VCC), Rajiv Gandhi Institute of Veterinary Education and Research (RIVER), Puducherry, 605009, India, Tel: +91 7708901932;

E-mail: vinodhinijayan@gmail.com

Keywords: Dogs; CKD; Increased level of serum creatinine; BUN and cholesterol

Copyright: (c) 2021 Vinodhini J, et al. This is an open-access article distributed under the terms of the Creative Commons Attribution License, which permits unrestricted use, distribution, and reproduction in any medium, provided the original author and source are credited.

https://www.peertechzpublications.com

Check for updates

\section{Abstract}

The present study on Chronic Kidney Disease (CKD) in dogs was aimed to record the incidence, risk factors, and clinical findings. Dogs irrespective of age, breed, sex with history, and clinical manifestations suggestive of CKD were selected and subjected to physical examination, urinalysis, hematology, and serum biochemistry. Based on these parameters twenty-nine dogs were identified as suffering from CKD and were classified into stage I, stage II, stage III, and stage IV as per the International Renal Interest Society (IRIS) staging system for CKD. Serum biochemistry revealed a significant increase in levels of serum creatinine, BUN, and cholesterol when compared to healthy controls. In conclusion, the prevalence of CKD in dogs was $2.5 \%$ and the article discussed the clinical and hemato-biochemical changes in CKD.

\section{Introduction}

Owning a canine pet has gained momentum as they serve as stress buster, a loyal companion and are considered a member of the family. Currently through the regularised veterinary services various disease conditions are being diagnosed in dogs. Among the various diseases recorded, the incidence of CKD seems to be the most common problem in geriatric dogs which causes increased morbidity and mortality in dogs (McGrotty, 2008). CKD is characterized by the development of progressive irreversible intra renal lesions and loss of renal functions. Hence the renal adaptations and extra renal changes contribute to the progression of this kidney disease which manifests as a clinical syndrome.

The International Renal Interest Society (IRIS) has proposed a 4-stage scoring system for CKD in dogs based on blood biochemical testing (fasting blood creatinine) and urinalysis results that categorize $\mathrm{CKD}$ cases to facilitate diagnosis, treatment, prognosis and research. Polyuria, polydipsia, anorexia, weight loss, dehydration, oral ulceration, vomiting and diarrhoea are noticed in CKD as the disease progresses to stage III and IV (Scottline, 2010). Estimation of serum creatinine is a valuable measurement for both prognostic and therapeutic 
purposes [1]. Proteinuria has been confirmed as a risk factor for increased mortality in dogs [2]. Although CKD is ultimately a progressive disorder, early diagnosis and therapeutic management may slow or halt the rate of progression and improve the patient recovery [3]. The recent researches show that Angiotensin- Converting Enzyme Inhibitors (ACEI) help to decrease proteinuria and improve longevity of kidney life span.

In Puducherry, mortality in dogs due to CKD has also been persistently recorded. A considerably large number of cases suffering from CKD are regularly registered and managed at the Small Animal unit of VCC. Hence detailed studies related to the incidence, risk factors and clinical signs of CKD in dogs have been planned to document. With this background the present study was undertaken with the following objectives:

1. To study the incidence and risk factors associated with CKD in dogs.

2. To study the hematology and serum biochemistry values in CKD (Stage III and stage IV) in dogs.

\section{Materials and methods}

\section{Study location}

This study was conducted over a period of six months at the Small Animal Medicine Unit of VCC, RIVER, Puducherry, India. The Climate of India consists of a wide range of weather conditions across a vast geographic scale and varied topography, making generalizations difficult. This study was carried out in the Southern part of India where the Climate is generally hotter and more humid due to its coasts.

\section{Experimental animal}

The experimental animals were the animals which regularly had come to the VCC for general check-up and treatment. Six apparently healthy dogs with normal vital signs and blood parameters were taken as a control group. Dogs irrespective of breed, age, sex with history, and clinical manifestations suggestive of CKD with serum creatinine levels $>1.4 \mathrm{mg} / \mathrm{dl}$ were selected for the disease group. Dogs that have shown mild illness such as hyperthermia, conjunctivitis and simple indigestion were eliminated as this study concentrated on Stage III and Stage IV of CKD (severe form of illness). The disease group didn't have the history of previous illness such as viral disease (Canine Distemper, Parvo-viral enteritis) and other diseases.

\section{Technical decision}

From the disease group those dogs with serum creatinine level 2.1-5 mg/dl (stage III CKD) and $>5 \mathrm{mg} / \mathrm{dl}$ (stage IV CKD) were selected and subjected for haematological and biochemical investigation. 2ml of blood was collected in EDTA vial (K3 EDTA $3.6 \mathrm{mg}$ - sample collection tube) for hematology and another $2 \mathrm{ml}$ of blood was collected in clot activator tube for estimating biochemical parameters. The experiment was carried out as per the following standard ethical procedure advocated by the Institutional Animals Ethics Committee (IAEC). (RIVER \# IAEC \#2021).

\section{Variables study}

Haematological variables: Include Haemoglobin [Hb] estimation using Sahli's acid hematin method, Packed cell volume [PCV] estimation using Wintrobe method, Total Leukocyte Count [TLC] estimation using haemocytometer, Differential leukocyte count [DLC] was done in the blood smear stained with leishman's staining technique and examined under the microscope, Blood parasite detection in the blood smear using leishman's staining technique was done.

Biochemical variables: Serum was separated from the clotted blood and biochemical parameters were estimated using kit method (enzymatic). Serum creatinine level was estimated by Mod. Jaffe Kinetic Method, Urea value was estimated by Mod. Berthelot Method and through this BUN value was calculated, total protein value was estimated by Biuret Method, albumin value was estimated by BCG Method and cholesterol value was estimated by CHOD/PAP Method. Based on the serum creatinine values, the International renal interest society (IRIS 2007) has classified CKD into four stages as follows:

Stage I (Nonazotemic) : Creatinine levels $<1.4 \mathrm{mg} / \mathrm{dL}$

Stage II (Mild Renal Azotemic) : Creatinine levels (1.4-2.0) $\mathrm{mg} / \mathrm{dL}$

Stage III (Moderate Renal Azotemic) : Creatinine levels (2.1-5.0) $\mathrm{mg} / \mathrm{dL}$

Stage IV (Severe Renal Azotemic) : Creatinine levels >5 mg/ $\mathrm{dL}$

\section{Statistical analysis}

The data obtained by the study were statistically analysed by one-way analysis of variance (ANOVA) using SPSS software version 17 for windows. The statistical significant was set at $\mathrm{P}$ $\leq 0.05$ typically.

\section{Results}

\section{Incidence and risk factors}

Out of 1160 dogs presented to the Small Animal Medicine unit, VCC, Mettupalayam, RIVER, the incidence of CKD recorded

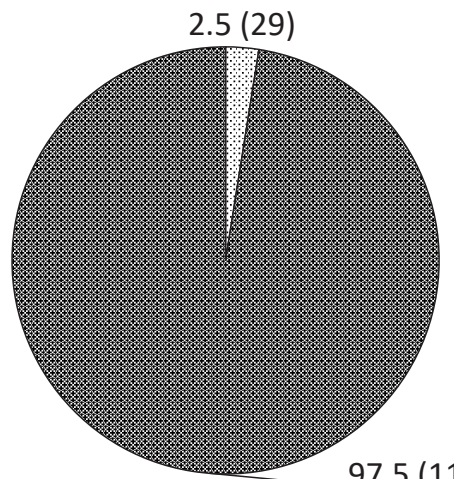

$97.5(1131)$ 
during the present study of six months was 2.5 percent (Figure 1). Out of twenty nine CKD dogs, the age wise incidence was recorded in five dogs $(17.24 \%)$ below seven years of age, seventeen dogs $(58.62 \%)$ between seven to less than twelve years of age and seven dogs $(24.14 \%)$ more than twelve years of age. (Figure 2). In the present study out of twenty nine dogs of CKD, seventeen $(58.62 \%)$ were male dogs and twelve $(41.38 \%)$ were females (Figure 3). The incidence of CKD in different breeds recorded were eleven dogs-non-descript (37.93\%), Spitz - nine (31.03\%), Labrador - four (13.79\%), German Shepherd, Rottweiler, Dalmation, Dachshund and beagle each - one $(3.45 \%)$ (Figure 4$)$. The type of food as a risk factor in CKD in the study group were nineteen dogs $(65.52 \%)$ fed with commercial food and homemade food and ten dogs (34.48\%) fed with only homemade food (Figure 5).

\section{Clinical findings}

The following clinical signs observed in the present study are illustrated in Table 1 and Figure 6 (a-f).

Out of twenty nine dogs of study group, the clinical signs observed in stage III were dull behaviour in eight dogs (88.89\%), anorexia in five dogs $(55.56 \%)$, pale mucous membrane in four dogs $(44.44 \%)$, vomiting in five dogs $(55.56 \%)$, polyuria and polydipsia in three dogs $(33.33 \%)$, oliguria in two dogs $(22.22 \%)$, melena in three dogs $(33.33 \%)$, weight loss in nine dogs $(100 \%)$, emaciation in three dogs $(33.33 \%)$, recumbency in

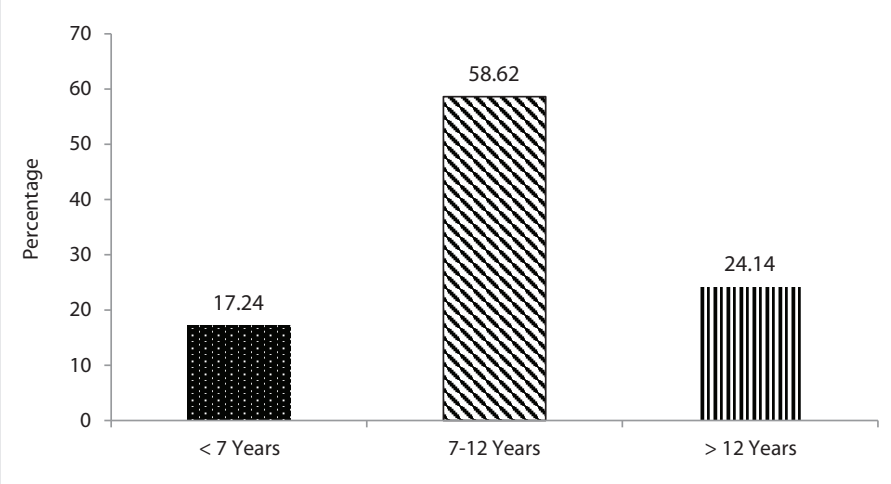

Figure 2: Age wise incidence of CKD in dogs.

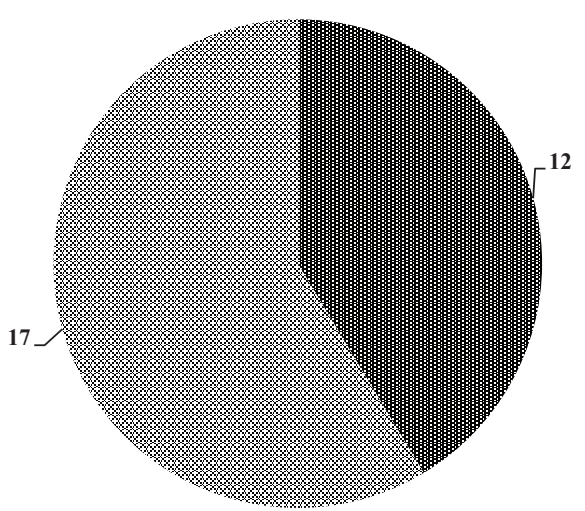

\& Female $x$ Male

Figure 3: Sex wise incidence of CKD in dogs.

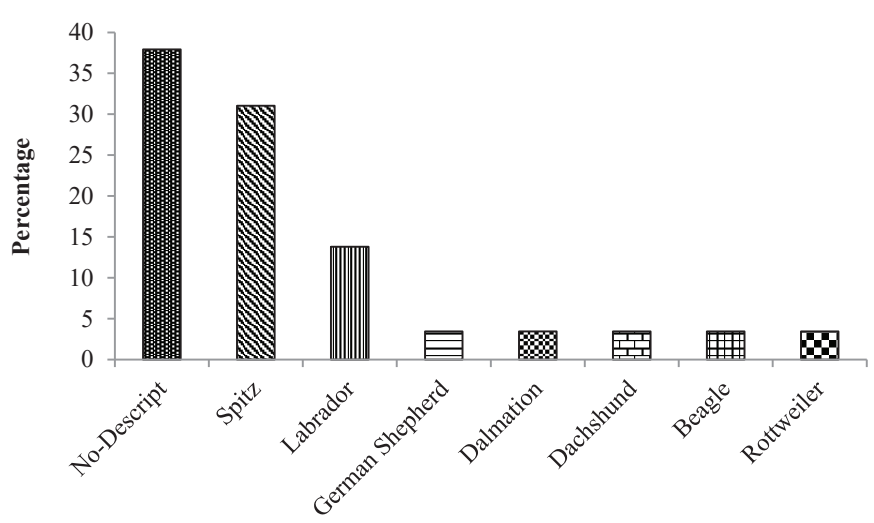

Figure 4: Breed wise incidences of CKD in dogs

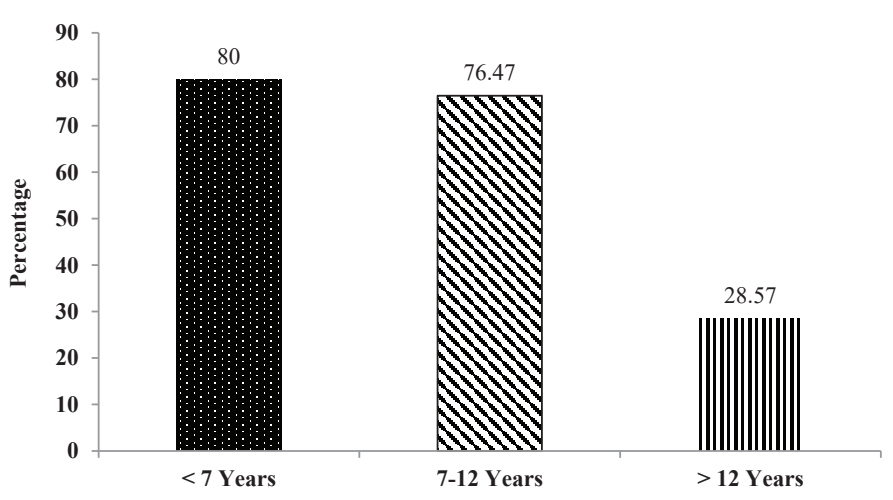

Figure 5: Commercial food as risk factor in CKD dogs in different age groups.

Table 1: Clinical signs in stage III and stage IV of CKD in dogs.

\begin{tabular}{|c|c|c|}
\hline Clinical findings & $\begin{array}{c}\text { Stage III } \\
(\%) \\
(n=9)\end{array}$ & $\begin{array}{c}\text { Stage IV } \\
(\%) \\
(\mathbf{n}=20)\end{array}$ \\
\hline Dullness & 88.89 & 80 \\
\hline Anorexia & 55.56 & 80 \\
\hline Weight loss & 100 & 100 \\
\hline Pale mucous membrane & 44.44 & 50 \\
\hline Vomiting & 55.56 & 65 \\
\hline Polydipsia and polyuria & 33.33 & 25 \\
\hline Recumbency & 11.11 & 35 \\
\hline Emaciated & 33.33 & 55 \\
\hline Melena & 33.33 & 75 \\
\hline Uremic breath & 11.11 & 40 \\
\hline Oliguria & 22.22 & 65 \\
\hline Mucosal ulcers & 0.00 & 10 \\
\hline Alopecia & 55.56 & 60 \\
\hline Dark yellowish urine & 33.33 & 55 \\
\hline Woebegone expression & 66.67 & 55 \\
\hline Slow gait & 55.56 & 65 \\
\hline Diarrhoea & 33.33 & 40 \\
\hline
\end{tabular}

one dog $(11.11 \%)$, uremic breath in one dog $(11.11 \%)$, alopecia in five dogs (55.56\%), dark yellowish urine in three dogs (33.33\%),

Citation: Vinodhini J, Abiramy Prabavathy A, Uma S, Barathiraja S, Rajkumar K, et al. (2021) Clinico-Biochemical findings associated with stage III and stage IV of Chronic Kidney Disease in dogs. Int J Vet Sci Res 7(2): 156-162. DOI: https://dx.doi.org/10.17352/ijvsr.000096 
woebegone expression in six dogs $(66.67 \%)$, staggering gait in five dogs $(55.56 \%)$ and diarrhoea in three dogs (33.33\%).

Clinical signs noticed in stage IV were dull behaviour in sixteen dogs $(80 \%)$, anorexia in sixteen dogs $(80 \%)$, pale mucous membrane in ten dogs $(50 \%)$, vomiting in thirteen dogs $(65 \%)$, polyuria and polydipsia in five dogs $(25 \%)$, oliguria in thirteen dogs (65\%), melena in fifteen dogs $(75 \%)$, weight loss in twenty dogs (100\%), emaciation in eleven dogs (55\%), recumbency in seven dogs $(35 \%)$, uremic breath in eight dogs $(40 \%)$, alopecia in twelve dogs $(60 \%)$, dark yellowish urine in eleven dogs $(55 \%)$, mucosal ulcer in two dogs $(10 \%)$, woebegone expression in eleven dogs $(55 \%)$, staggering gait in thirteen dogs (65\%) and diarrhoea in eight dogs $(40 \%)$.

\section{Urinalysis}

In stage III, dark yellowish urine was observed in three dogs $(33.33 \%)$, urine was cloudy in three dogs $(33.333 \%)$, the foul odour was noticed in four dogs $(44.44 \%)$, three dogs $(33.33 \%)$ were positive for urine glucose and two dogs $(22.22 \%)$ were positive for ketone bodies in the urine.

In stage IV, dark yellowish urine was observed in eleven

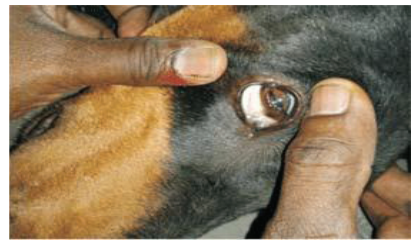

(6a)

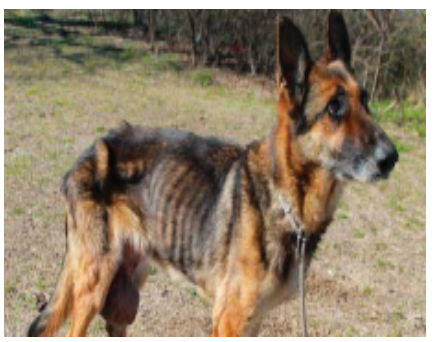

(6c)

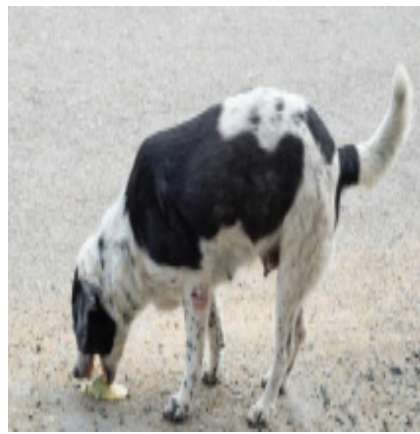

(6e)

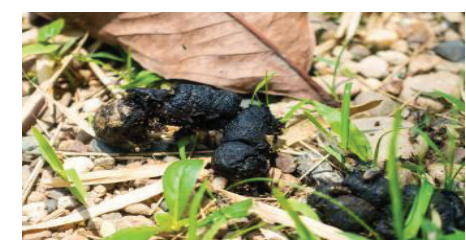

(6b)

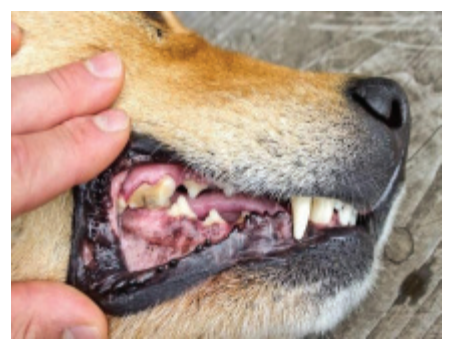

(6d)

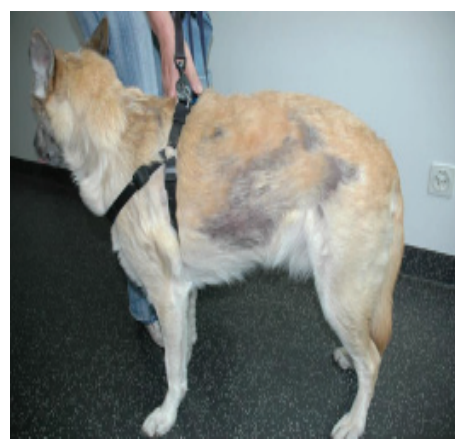

(6f)
Figure 6 (a-f): Clinical signs in Stage III and Stage IV of CKD in dogs.

(6a) Pale mucous membrane

(6b) Melena

(6c) Emaciation

(6d) Mucosal ulcers

(6e) Vomitus

(6f) Poor coat quality. dogs $(55 \%)$, urine was cloudy in thirteen dogs $(65 \%)$, the foul odour was noticed in eleven dogs $(55 \%)$, thirteen dogs $(65 \%)$ were positive for urine glucose, nine dogs $(45 \%)$ were positive for ketone bodies in the urine and blood was present in the urine of three dogs (15\%).

Urine protein values of the control group and stage III and stage IV of CKD are given in Table 2 . Urinalysis characteristics in stage III and stage IV of CKD in dogs in Table 3.

Control dogs were negative for urine protein, urine glucose and ketone bodies. Urine protein of $+(30 \mathrm{mg} \%)$ was recorded in three dogs $(33.33 \%)$ in stage III and three dogs $(15 \%)$ in stage IV.

Urine protein of $++(100 \mathrm{mg} \%)$ was noticed in two dogs $(22.22 \%)$ of stage III and four dogs $(20 \%)$ of stage IV.

Urine protein of $+++(300 \mathrm{mg} \%)$ was recorded in one dog $(11.11 \%)$ of stage III and six dogs $(30 \%)$ of stage IV.

Urine protein of $++++(1000 \mathrm{mg} \%)$ was noticed in one dog $(11.11 \%)$ of stage III and four dogs $(20 \%)$ of stage IV.

\section{Haematological findings}

The most common haematological findings in stage III and stage IV of CKD dogs were decreased haemoglobin values, decreased PCV values and increased TLC. Levels of neutrophils increased significantly in dogs with CKD. The mean \pm S.E values of haematological findings of control group and stage III and IV of CKD are given in the Tables 4,5. The disease group was also negative for blood parasites.

\section{Biochemical findings}

The mean \pm S.E values of serum biochemistry observed in the control group and stage III and stage IV of CKD dogs are given in Table 6. A high significant increase in serum creatinine values, blood urea nitrogen values and serum cholesterol values were recorded in stage III and stage IV when compared to the control group. A significant decrease in albumin values was recorded in stage IV of CKD dogs when compared to the control group and stage III of CKD dogs.

\section{Discussion}

\section{Incidence and factors}

The incidence of CKD was 2.5 per cent out of 1160 cases whereas Bartlett, et al. [4] recorded 5.8 percent of CKD in dogs. However, O'Neil, et al. (2013) recorded a prevalence of 0.05$3.74 \%$ of CKD in dogs. The highest incidence of 58.62 per cent was recorded between seven to less than twelve years of age group and the least was recorded below seven years which very well supports the theory of CKD progression from early subclinical kidney damage to clinical disease as per Bartges and Polzin [5]. Polzin and Osborne (1986) reported that the prevalence of CKD increases with advancing age from 5-6 years onwards in geriatric dogs. Macdougall, et al. (1986) and Robertson (1986) estimated that $2.4 \%$ and $15 \%$ of dogs aged 10 years and above 10 years suffer from CKD respectively. Out

Citation: Vinodhini J, Abiramy Prabavathy A, Uma S, Barathiraja S, Rajkumar K, et al. (2021) Clinico-Biochemical findings associated with stage III and stage IV of Chronic Kidney Disease in dogs. Int J Vet Sci Res 7(2): 156-162. DOI: https://dx.doi.org/10.17352/ijvsr.000096 
Table 2: Proteinuria description in stage III and stage IV of CKD in dogs.

\begin{tabular}{|c|c|c|c|c|c|}
\hline \multirow{2}{*}{ Group } & \multicolumn{5}{|c|}{ Proteinuria } \\
\hline & Negative & $+(30 \mathrm{mg} \%)$ & ++(100mg\%) & $+++(300 \mathrm{mg} \%)$ & $++++(1000 \mathrm{mg} \%)$ \\
\hline Stage III $(n=9)$ & 22.22 & 33.33 & 22.22 & 11.11 & 11.11 \\
\hline $\begin{array}{c}\text { Stage IV } \\
(\mathrm{n}=20)\end{array}$ & 15 & 15 & 20 & 30 & 20 \\
\hline
\end{tabular}

Table 3: Urinalysis characteristics in stage III and stage IV of CKD in dogs.

\begin{tabular}{|c|c|c|}
\hline Parameters & Stage III (\%)n=9 & Stage IV (\%)n=20 \\
\hline Dark yellowish urine & 33.33 & 55 \\
\hline Cloudy & 44.44 & 65 \\
\hline Foul odour & 44.44 & 55 \\
\hline Presence of glucose & 33.33 & 65 \\
\hline Presence of ketone bodies & 22.22 & 45 \\
\hline Presence of blood & 0.00 & 15 \\
\hline
\end{tabular}

Table 4: Haematological profile in stage III and stage IV of CKD in dogs.

\begin{tabular}{|c|c|c|c|}
\hline Group & Hb (g/d) & PCV $(\%)$ & TLC $(\times 1000 / \mathbf{c m m})$ \\
\hline $\begin{array}{c}\text { CONTROL } \\
(n=6)\end{array}$ & $13.64 \pm 0.39^{a}$ & $38.65 \pm 0.85^{\mathrm{a}}$ & $13.11 \pm 1.88^{\mathrm{a}}$ \\
\hline $\begin{array}{c}\text { STAGE III } \\
(n=9)\end{array}$ & $8.47 \pm 0.65^{\mathrm{b}}$ & $26.67 \pm 2.27^{\mathrm{b}}$ & $14.13 \pm 1.44^{\mathrm{b}}$ \\
\hline $\begin{array}{c}\text { STAGE IV } \\
(\mathrm{n}=20)\end{array}$ & $8.02 \pm 0.33^{\mathrm{c}}$ & $25.04 \pm 1.03^{\mathrm{c}}$ & $17.68 \pm 1.54^{\mathrm{c}}$ \\
\hline
\end{tabular}

The values bearing different superscript within a column differ significantly at $\mathrm{P}<0.05$

Table 5: Leukogram description in stage III and stage IV of CKD in dogs.

\begin{tabular}{|c|c|c|c|c|c|}
\hline \multicolumn{7}{|c|}{ Absolute Differential leucocyte count } \\
\hline Group & $\begin{array}{c}\text { DLC } \\
\text { (Neutrophil) }\end{array}$ & $\begin{array}{c}\text { DLC } \\
\text { (Leucocyte) }\end{array}$ & $\begin{array}{c}\text { DLC } \\
\text { (Monocyte) }\end{array}$ & $\begin{array}{c}\text { DLC } \\
\text { (Eosinophil) }\end{array}$ & $\begin{array}{c}\text { DLC } \\
\text { (Basophil) }\end{array}$ \\
\hline $\begin{array}{c}\text { CONTROL } \\
(n=3)\end{array}$ & $8.69 \pm 1.38^{\mathrm{a}}$ & $3.52 \pm 0.47^{\mathrm{a}}$ & $0.65 \pm 0.24^{\mathrm{a}}$ & $0.1 \pm 0.02^{\mathrm{a}}$ & $0.0 \pm 0.0^{\mathrm{a}}$ \\
\hline $\begin{array}{c}\text { STAGE III } \\
(\mathrm{n}=9)\end{array}$ & $11.03 \pm 1.47^{\mathrm{b}}$ & $2.79 \pm 0.29^{\mathrm{a}}$ & $0.66 \pm 0.09^{\mathrm{a}}$ & $0.1 \pm 0.04^{\mathrm{a}}$ & $0.0 \pm 0.0^{\mathrm{a}}$ \\
\hline $\begin{array}{c}\text { STAGE IV } \\
(\mathrm{n}=20)\end{array}$ & $14.83 \pm 1.49^{\mathrm{c}}$ & $2.73 \pm 0.29^{\mathrm{a}}$ & $0.73 \pm 0.04^{\mathrm{a}}$ & $0.09 \pm 0.06^{\mathrm{a}}$ & $0.0 \pm 0.0^{\mathrm{a}}$ \\
\hline
\end{tabular}

The values bearing different superscript within a column differ significantly at $\mathrm{P}<0.05$

Table 6: Serum biochemistry profile in stage III and stage IV of CKD in dogs.

\begin{tabular}{|c|c|c|c|c|c|}
\hline Group & $\begin{array}{c}\text { Creatinine } \\
(\mathbf{m g} / \mathbf{d l})\end{array}$ & $\begin{array}{c}\text { BUN } \\
(\mathbf{m g} / \mathbf{d l})\end{array}$ & $\begin{array}{c}\text { Total protein } \\
(\mathbf{g} / \mathbf{d l})\end{array}$ & $\begin{array}{c}\text { Albumin } \\
(\mathbf{g} / \mathbf{d l})\end{array}$ & $\begin{array}{c}\text { Cholesterol } \\
(\mathbf{m g} / \mathbf{d l})\end{array}$ \\
\hline $\begin{array}{c}\text { CONTROL } \\
(n=6)\end{array}$ & $0.74 \pm 0.11^{\mathrm{a}}$ & $18.12 \pm 1.82^{\mathrm{a}}$ & $6.45 \pm 0.74^{\mathrm{a}}$ & $2.71 \pm 0.33^{\mathrm{a}}$ & $205.07 \pm 13.83^{\mathrm{a}}$ \\
\hline $\begin{array}{c}\text { STAGE III } \\
(\mathrm{n}=9)\end{array}$ & $4.39 \pm 0.23^{\mathrm{b}}$ & $66.65 \pm 8.82^{\mathrm{b}}$ & $6.99 \pm 0.09^{\mathrm{a}}$ & $2.26 \pm 0.11^{\mathrm{a}}$ & $289.55 \pm 17.03^{\mathrm{b}}$ \\
\hline $\begin{array}{c}\text { STAGE IV } \\
(\mathrm{n}=20)\end{array}$ & $17.71 \pm 1.69^{\mathrm{c}}$ & $102.62 \pm 5.94^{\mathrm{c}}$ & $7.21 \pm 0.07^{\mathrm{a}}$ & $2.18 \pm 0.06^{\mathrm{a}}$ & $357.78 \pm 14.09^{\mathrm{c}}$ \\
\hline
\end{tabular}

The values bearing different superscript within a column differ significantly at $\mathrm{P}<0.05$

of twenty nine dogs with CKD, 58.62 per cent were male dogs and 41.38 per cent were females. Non-descript dogs showed the highest incidence of 37.93 per cent and Rottweiler dogs, Dalmation, Dachshund, Beagle and German Shepherd dogs showed the least incidence of 3.45 per cent in the present study. This increase in male dogs and increased incidence in non-descript dogs may be due to over representation of the sex. The incidence of CKD was highest in dogs fed with commercial and home-made food which was 65.52 per cent and least in dogs fed with homemade food alone which was 34.48 per cent. Bleiler and Schell [6] reported that an increase in serum creatinine is directly proportional to the increase in dietary intake of meat.

\section{Clinical signs (Stage III)}

Dullness in 88.89 per cent, anorexia in 55.56 per cent, pale mucous membrane 44.44 per cent, vomiting 55.56 per cent, polyuria and polydipsia in 33.33 per cent, oliguria in 22.22 per cent, melena in 33.33 per cent, weight loss in 100 per cent, emaciation in 33.33 per cent, recumbency in 11.11 per cent, uremic breath in 11.11 per cent, alopecia in 55.56 per cent, dark yellowish urine in 33.33 per cent, woebegone expression in 66.67 per cent, staggering gait in 55.56 per cent and diarrhoea in 33.33 per cent was recorded in stage III CKD dogs. Dullness, anorexia, weight loss, emaciation and vomiting showed an increasing trend as the disease gets worsened. The above clinical findings such as weight loss and dullness are consequences of inadequate calorie intake, insulin resistance and combined catabolic effects of uremia and intestinal malabsorption as described by Liao, et al. (2012). These clinical impressions suggest that naturally occurring CKD in dogs is a progressive malady as per Delmar, et al. [7]. Similar findings were also recorded by Polzin, et al. (2005), Nelson and Couto (2009) and Bartlett, et al. (2010).

\section{Clinical signs (Stage IV)}

Dullness in 80 percent, anorexia in 80 percent, the pale mucous membrane in 50 percent, vomiting in 65 percent, polyuria and polydipsia in 25 percent, oliguria in 65 percent, melena in 75 percent, weight loss in 100 percent, emaciation in 55 percent, recumbency in 35 percent, uremic breath in 40 percent, alopecia in 60 percent, dark yellowish urine in 55 percent, mucosal ulcer in 10 percent, woebegone expression in 55 percent, slow gait in 65 percent and diarrhoea in 40 percent was observed in stage IV CKD dogs. The clinical signs in stage IV were progressively and significantly increased when compared to stage 3. The recorded clinical syndrome at this stage is the consequences of uremia. Anorexia, vomiting, melena, uremic breath and mucosal ulcers are as a result of stimulation of CTZ in medulla suggesting circulating factors of NPN as one cause [8]. Oral ulcers are attributed to ammonia released by bacterial action on urea [9]. Uremic breath indicates that dimethylamine is responsible for this odour in human patients (Simenhoff, et al. 1977). Melena is as a result of GIT bleeding known to contribute to increased urea in blood as a consequence of increased GIT absorption of nitrogenous compounds (Dibartola, et al., 1983). The above clinical findings are in accordance with Mrudula, et al. (2005), Rubin (1997) and Eschbach and Adamson (2012).

\section{Urinalysis}

Proteinuria was recorded in all stage III and stage IV of CKD dogs. + (30 mg \%), ++ (100 mg \% $),+++(300 \mathrm{mg} \%)$ and $+++(1000 \mathrm{mg} \%)$ proteinuria were recorded in stage III and stage IV. Proteinuria is a strong, independent risk factor for the progression of renal disease in dogs (Brown, et al. 2003) which is in accordance with the present study. However, proteinuria 
may decline as renal dysfunction worsens and so may be less frequent in animals in stages III and IV (IRIS) and similar changes have been observed in stages III and IV in the present study. Not only proteinuria is a marker of kidney damage, but it is also responsible for progressive kidney injury. The increase in urinary protein either by damage to the glomerular capillary wall or by a decrease in tubular reabsorption of protein causes injury to renal tubular cells. Serum creatinine is elevated when there is a significant reduction in the glomerular filtration rate or when urine elimination is obstructed. D'Amico G, Bazzi C: Pathophysiology of proteinuria. Kidney International 63: 809825, 2003.

In stage III CKD dogs, dark yellowish urine in 33.33 percent, urine was cloudy in 33.333 percent, foul odour in 44.44 percent, 33.33 percent were positive for urine glucose and 22.22 percent were positive for ketone bodies in the urine was recorded.

In stage IV CKD dogs, dark yellowish urine 55 percent, urine was cloudy in 65 percent, foul odour in 55 percent, 65 percent was positive for urine glucose, 45 percent was positive for ketone bodies in the urine and blood in the urine in 15 percent was observed.

\section{Haematological findings}

A high significant decrease in mean $\mathrm{Hb}$ values was recorded in stage III and stage IV of CKD dogs, when compared to the control group. A high significant decrease in mean PCV values was recorded in stage III and stage IV when compared to the control group.

The blood picture revealed a significant decrease in $\mathrm{Hb}$ and PCV, which concur with Cowgill [10] and Nandy and Pradhan (2006). This decline in haemoglobin and packed cell volume is attributed to gastrointestinal bleeding, deficiency of erythropoietin from the kidney as per Krawiec (1996) and Martiarena, et al. (2000), reduced RBC survival, uremic inhibitors of erythropoiesis, bone marrow fibrosis and nutritional deficiencies as per Cowgill (1992).

A significant increase in the total leucocyte count was recorded in stage III and stage IV of CKD when compared to the control group. Leucocytosis is a common finding in CKD, which is an indicator for the progression of kidney disease, which supports the present study in accordance with Erlinger, et al. (2003).

\section{Biochemical findings}

Serum creatinine: A highly significant increase in serum creatinine values was recorded in stage III and stage IV when compared with the control group. A high significant increase in the values of serum creatinine in stage IV was recorded when compared to stage III CKD dogs. A similar increase in creatinine levels was observed by Srinivasan (1990) during studies in canine renal insufficiency. Serum creatinine levels are commonly used to measure kidney dysfunction and are the basis for the IRIS staging system (Grauer, 2005).

Blood urea nitrogen: Elevated levels of BUN were observed in stage III and stage IV in the present study when compared to the control group. A high significant increase in blood urea nitrogen values in stage IV was recorded when compared to stage III CKD dogs. The present finding is in agreement with Oburai, et al. (2015) and Cowgill [10]. Polzin (2007) viewed BUN as a surrogate marker of retained uremic toxins and added that BUN concentrations increase with increased protein intake, declining renal function and gastrointestinal haemorrhage and enhanced protein catabolism. Adams [11] and Kaneko, et al. (2008) reported that raised serum BUN levels in CRF occur when there is severe renal impairment.

Total protein: Stage III and stage IV of CKD dogs had total protein values within the normal range. A significant increase in stage IV $(7.21 \pm 0.07)$ CKD was recorded when compared with a control group and stage III. Moderate to severe proteinuria was noticed in stage III and stage IV. Hence this significant change may be attributed to increase in globulin part, slow rate of protein loss and dehydration in stage III and stage IV CKD dogs. Similar changes were observed in serum total proteins by Oburai, et al. (2015) during their studies in CRF dogs.

Albumin: A significant decrease in albumin values was recorded in stage IV of CKD dogs when compared to the control group and stage III of CKD dogs. However, there was a mild difference recorded in stage III when compared to the control group. The present finding is in accordance with Bush (1983) and Vaden (2005) who recorded reduced serum albumin levels in renal failure cases caused by an increased filtration of albumin through the glomeruli and owing to its molecular size. McGrotty (2008) reported that persistent micro albuminuria may be used as a possible marker of early renal disease in healthy animals that have an increased risk of renal disease. Parrah, et al. (2011) reported that persistent Micro Albuminuria (MA) is an indicator of glomerular damage associated with early progressive renal disease [12-16].

Cholesterol: A high significant increase in serum cholesterol values were recorded in stage III and stage IV when compared to the control group. A high significant increase in the values of serum cholesterol in stage IV was recorded when compared to stage III CKD dogs.

\section{B-mode and Doppler ultrasound of CKD in dogs}

Ultrasound is the imaging test of choice for renal evaluation, because it provides information about the position, size, shape, internal architecture and hemodynamics of the kidneys without harming the patient. In CKD, the main findings observed in B-mode ultrasound images are increased cortical echogenicity, loss of corticomedullary differentiation, reduced renal volume and irregular renal contour, and when these changes are associated, they are indicative of end-stage renal disease. However, the cause of kidney disease cannot be determined by ultrasonography, but must be confirmed by means of biopsy, although the presence of ultrasonographic changes indicative of the end-stage of the disease may contraindicate this procedure. The Doppler ultrasound test complements the ultrasonic B-mode examination and enables the assessment of renal perfusion based on a calculation of the hemodynamic indices, which are increased in cases of chronic kidney lesions, with higher values in the most severe cases. Thus, ultrasound examinations are not only useful in diagnostics but also play an important role in defining the prognosis of patients with CKD.

Citation: Vinodhini J, Abiramy Prabavathy A, Uma S, Barathiraja S, Rajkumar K, et al. (2021) Clinico-Biochemical findings associated with stage III and stage IV of 
Ultrasound has emerged as the primary imaging modality in conditions where either renal obstruction or renal medical disease is suspected on the basis of clinical and laboratory findings. In urinary tract obstruction, pathophysiologic changes affecting the pressure in the collecting system and kidney perfusion are well understood and form the basis for the correct interpretation of real-time US and Colour Doppler Duplex Sonography (CDDS). Ultrasound is very sensitive for the detection of collecting system dilatation ("hydro-nephrosis"); however, obstruction is not synonymous with dilatation, as either obstructive or non-obstructive dilatation may be present. To differentiate these conditions, CDDS with measurement of the Resistive Index (RI) in the intra-renal arteries is extremely helpful, as obstruction (except in the per-acute stage) leads to intra-renal vasoconstriction with a consecutive increase of the RI above the upper limit of 0.7 , whereas non-obstructive dilatation does not. Diuretic challenge to the kidney may further enhance these differences in RI between obstruction and dilatation. Based on these findings, the present value of US and CDDS in the assessment of the patient with flank pain or renal colic is suggested, especially with respect to promising results for spiral CT and based on cost analysis. In renal medical disease, distinguishing different pathologic conditions using gray-scale US and CDDS (RI) criteria is still very difficult. Nevertheless, US is the fist-line imaging modality in the patient with renal insufficiency.

\section{Conclusion}

The incidence of CKD in dogs was $2.5 \%$ in Puducherry. Classical clinical findings in stage III and stage IV CKD dogs were weight loss, vomiting, melena, polyuria \& polydipsia(stage III), oliguria(stage IV), anaemia, anorexia, decreased $\mathrm{Hb}$ and PCV, increased TLC, increased serum creatinine, BUN and cholesterol and decreased albumin. Maximum number of cases was recorded at 7 to 12 years of age. Hence, this study emphasizes regular check-up and screening for CKD in both middle aged and older dogs. Risk factors (age and diet), serum creatinine and urinary protein may be taken as prognostic marker for the early diagnosis of CKD in dogs. Renal diseases, especially $\mathrm{CKD}$, are common in canine and feline medicine. The Renin-Angiotensin-Aldosterone System (RAAS) plays a pivotal role in these conditions in the development of renal lesions and the progression of kidney dysfunction. Angiotensin-Converting Enzyme Inhibitors (ACEI) are currently considered as the most efficient agents in therapeutic strategies. The benefit of an ACEI treatment can be explained by at least three mechanisms: ACEI limit systemic and glomerular capillary hypertension, have an antiproteinuric effect, and retard the development of glomerulosclerosis and tubulointerstitial lesions. These effects have been studied in dogs and cats, and there is now some evidence to support the recommendation of ACEI therapy in dogs and cats with CKD. Treating proteinuria in dogs using ACEI reduces the progression of Chronic Kidney Disease (CKD) which improves the longevity of kidney life span. Nevertheless the prescription of ACEI in such patients should take into account the potential influence of renal impairment on ACEI disposition, and adverse effects on the renal function itself (especially hypotension and acute reductions in glomerular filtration rate). The risk of drug interaction with diuretics, nonsteroidal anti-inflammatory drugs and anesthetics, should not be overestimated. Furthermore, hypotension may occur in patients on a low sodium diet.

\section{Acknowledgement}

The authors are thankful to the Dean, Rajiv Gandhi Institute of Veterinary Education and Research for providing necessary permission and extending the facilities for successfully completing this work.

\section{References}

1. Allen $T$, Jaenke, R, Fettman $M$ (1987) A technique for estimating progression of chronic renal failure in the dog. J American Vet Med Assoc 190: 866-868. Link: https://bit.ly/3FJDIAs

2. Brown SA, Brown CA, Crowell WA (2000) Effects of dietary polyunsaturated fatty acid supplementation in early renal insufficiency in dogs. J Lab Clin Med 135: 275-286. Link: https://bit.ly/3xvSjap

3. Bartges JW (2012) Chronic kidney disease in dogs and cats. Vet Clin North Am Small Anim Pract 42: 669-692. Link: https://bit.ly/30Pu0Yy

4. Bartlett PC, Van Buren JW, Barlett AD (2010) Case-control study of risk factors associated with feline and canine chronic kidney disease. Vet Med Int 1242 1249. Link: https://bit.ly/2Zl8Wc4

5. Bartges J, Polzin DJ (2011) Nephrology and Urology of Small Animals. Oxford Wiley-Blackwell Publisher 909-920. Link: https://bit.ly/3l3UsVL

6. Bleiler RA, Schell HP (1962) Creatinine excretion: Variability and relationships to diet and body size. J Lab Clin Med 59: 945-955. Link: https://bit.ly/3xgl1fc

7. Delmar R, Finco Scott A, Brown Cathy A, Brown Wayne A, Crowell Tanya A, et al. (1999) Progression of Chronic Renal Disease in the dog. J Vet Intern Med 13: 516-528. Link: https://bit.ly/3raGl4R

8. Borison HL, Herbertson LM (1959) Role of medullary emetic chemoreceptor trigger zone (CT zone) in postnephrectomy vomiting in dogs. Am J Physiol 197: 850-852. Link: https://bit.ly/30X3E7d

9. Black DA (1970) A Perspective on Uremic Toxins. JAMA 126: 906-909. Link: https://bit.ly/3oUtv82

10. Cowgill LD (2004) Anemia of Chronic Kidney Disease. In: Tilley, L.P and Smith, F.W.K. eds. Blackwell's 5-minute veterinary consult: canine and feline. $4^{\text {th }}$ edn Ames: Blackwell publishing: 80-81

11. Adams LG (1997) Chronic renal failure. In text book of the 5 minute veterinary consultant - canine and feline. Edited by Tilley LP and Smith JF, Publisher, Williams and Williams, Philadelphia 1156-1157.

12. Anjaria J, Parabia M, Dwivedi SK (2002) EthnovetHeritage. Pathik Enterprise, Saijpur, Ahmedabad.

13. Borku MK, kurtaede A, Aydn Y, Durgut R, Pekkaya S, et al. (2000) Clinical Laboratory and Pathological findings in cats and dogs exhibiting CRF signs. A $\vee$ Vet Fakultesi Ic Hastalker Anabilim Dal Ankara 47: 281- 289. Link: https://bit.ly/3।3CNxi

14. Center SA, Smith CA, Wilkinson E, Erb HN, Lewis RM (1987) Clinicopathologic renal immune fluorescent, and light microscopic features of glomerulonephritis in the dog: 41 cases $(1975$ - 1985). J Am Vet Med Assoc 190: 81-90. Link: https://bit.ly/3HHmAYe

15. Coles EH (1986) Veterinary Clinical pathology, $4^{\text {th }}$ ed. Philadelphia, W.B. Saunders CO., U.S.A 171-202.

16. Elliott J (2007) Staging chronic kidney disease. In: Elliott J, GrauerGF, eds. BSAVA Manual of Canine and Feline Nephrology and Urology, $2^{\text {nd }}$ ed Quedgeley: British Small Animal Veterinary Association 161-166.

Citation: Vinodhini J, Abiramy Prabavathy A, Uma S, Barathiraja S, Rajkumar K, et al. (2021) Clinico-Biochemical findings associated with stage III and stage IV of 